\title{
JOSEP M. MILLÀS-RAURELL, HOME DE TEATRE: LES INSURRECCIONS FRUSTRADES
}

\author{
NÚRIA SANTAMARIA
}

\begin{abstract}
Josep M. Millàs-Raurell (Barcelona I896-197I) was one of the most active intellectuals in Catalonia during the 1920 and I930s. His desire to attain a cultural system comparable to European norms became solidified in the field of theater in his work in translation, management, and artistic creation and was grounded in positions that were radically critical of existing models of theatrical production and consumption. His silence, almost absolute, following the war would convert him into a paradigm of yet another intellectual rebellion that was cast aside with the conflict that began in 1936 .
\end{abstract}

$\mathrm{E}_{1}$ 30 de gener de 1997, el Centre Català del PEN Club va celebrar un petit acte per commemorar el centenari del naixement d'un dels qui l'any 1922 van fundar la delegació d'aquesta entitat a Catalunya: Josep M. Millàs-Raurell, que va continuar com a secretari del Centre fins al 1939. L'escassa afluència de públic a la reunió, comentada amb àcida ironia per Agustí Pons al diari de l'endemà, era el reble d'un oblit que l'any de retard amb què es va organitzar la vetllada d'evocació i homenatge (l'escriptor havia nascut el 6 de setembre de 1896 ) ja posava en evidència (Pons 42). Un oblit del qual només se n'havia dolgut amb puntualitat Albert Manent a l'Avui en un article on reclamava atenció i estudi per a l'obra de Millàs-Raurell. ${ }^{1}$

Com és sabut, la mala memòria respecte a la pròpia tradició cultural és quasi constitutiva de la tradició catalana mateixa. Així i tot, enllà de les reincidents amnèsies històriques, hi ha alguna cosa en la trajectòria de Millàs-Raurell, en l'enigmàtic silenci literari autoimposat de després de la guerra i l'exili, que resulta pertorbadora. Desconèixer-ne les causes precises, la dificultat de dilucidar fins a quin punt el silenci va ser provocat per imperatius íntims i personals o si va ser producte de la guerra $i$ la maltempsada franquista o de totes dues coses alhora, incita a convertir la figura de Millàs-Raurell en paradigma de les insurreccions frustrades de tota una plèiade d'homes de lletres que, a retaló dels

I Tot i que cal un estudi aprofundit d'aquest dramaturg, seria injust oblidar les estimables aportacions de Francesc Curet, Xavier Fàbregas i Enric Gallén. 
esforços modernistes i noucentistes per inventar una cultura nacional, maldaren per empènyer la sedimentació “revolucionària” d'una cultura normal a Catalunya, homologable amb la de qualsevol país europeu.

L'ulterior mutisme de Millàs crida l'atenció perquè ell precisament va ser un dels individus, compromesos en la tasca normalitzadora, que més projecció pública va aconseguir durant les dècades dels vint i dels trenta, tant per l'índole de la seva labor literària, ramificada en el conreu de la poesia, la prosa i el teatre, com per la diligent participació en els grups de La Revista, del Pen Club, dels Amics de la Poesia entre d'altres organitzacions. De fet, la imatge que solia transcendir de l'escriptor a la premsa de l'hora era la d'un autèntic escarràs de la cultura: "Millàs-Raurell” — anotava un dels cronistes de La Veu de Catalunya- "és un home extraordinàriament inquiet, que sempre en du una de cap i sempre porta pressa. Tanta pressa porta sempre que, si ha de publicar un llibre de versos, dóna abans tres o quatre lectures; si ha d'estrenar una comèdia, la publica dues vegades i en dóna una representació privada; si us ha de dir una cosa avui, us la diu tres o quatre dies abans. És d'aquells homes que els veieu passar, fugint per un carrer, i penseu: aquest, havia de passar demà” (Martí Martell 5).

El comentari podria semblar una simpàtica facècia si no fos que la descripció s'ajusta força al tragí de conferències, recitals, llibres escrits... que les publicacions periòdiques de l'època varen consignar. Valgui com exemple, sinó, la resposta que l'autor donava al reporter de La Humanitat quan a les acaballes de I93I li demanava un avanç dels projectes teatrals per a la temporada següent:

Fa una temporada que escric molt poc. He traduït de l'alemany, com a exercici, El gran Hotel, de la popular escriptora alemanya Vicki Baum. És una obra que ha tingut un grandiós èxit a l'estranger i que em sembla que ha de donar, si es munta de manera apropiada, un gran rendiment. Treballo ara també en dues comèdies, El marxant d'il.lusions i Una comèdia per a senyores. Tinc molt avançada també l'opereta que faig amb el mestre Dotras Vila: Els senyors les volen rosses. (Martí Ferrer 4 )

Les paraules de Millàs-Raurell permeten entreveure i treure a rotlle alguns aspectes característics de la seva manera de concebre la feina de l'escriptor en general i del teatrista en particular, aspectes com ara la versatilitat productiva o la infatigable divulgació de models forans sobre els quals de seguida tornaré. Abans, però, en aquest context, val la pena marcar amb pedra blanca l'abast de la seva vocació dramàtica, perquè, a pesar dels tres llibres de poesia editats i del seu obvi interès per la novel·la i la narració curta, empeltades en els models de Joyce i de Maurois entre altres, ${ }^{2}$ "per damunt de tot”, deia, “em crec

\footnotetext{
${ }^{2}$ Sobre aquest particular, vegeu Iribarren.
} 
un home de teatre" (Martí Martell 5), i el testimoni és prou digne de crèdit si es considera que s'emetia a les envistes de l'estrena de $\mathrm{La}$ Llotja al teatre Novetats el I928, que és la feta que el consagraria com a dramaturg amb tots els ets i uts (Martí Martell 5 ).

Tampoc no és casual, em sembla, que Millàs-Raurell es definís com a "home de teatre" i no com a simple autor. Des dels inicis i amb independència de la qualitat i la fortuna dels seus assaigs, MillàsRaurell va entendre que la tria de la modalitat dramàtica no era una qüestió retòrica i que la publicació dels textos era insuficient sense una representació que vivifiqués l'escrit: “ ... jo he cregut tothora que una obra de teatre ha de triomfar o fracassar en escena" (Martí Martell 5). ${ }^{3}$ Per això davant la impermeabilitat de les empreses barcelonines, optà per estrenar les primeres versions d'algunes de les seves obres fora de l'àmbit comercial, ${ }^{4}$ i per això no va mossegar-se la llengua a l'hora de criticar la ineficàcia d'uns premis de teatre institucionals que, després d'uns quants anys d'atorgar-se, encara no havien aconseguit garantir l'estrena en condicions de les peces guardonades: "[el Premi Ignasi Iglésias] és anualment un crit de desesperació que el nostre teatre decorós llança per damunt de la misèria a què el condemnen entre tots" (“El Premi” 2). En l'agra denúncia de Millàs-Raurell, hi pesava probablement l'experiència personal: l'autor havia guanyat l'Iglésias el $1934 \mathrm{amb}$ El món en què vivim, sense haver pogut arribar a veure mai l'obra dalt de l'escenari en negar-se a acceptar les condicions artístiques que la companyia de Mercè Nicolau i Ramon Martori havien pretès imposar-li, perquè "entenc que a l'escena, avui per avui a Catalunya," aclaria el dramaturg, "l'únic que ha de manar és l'autor" (M. 2).

S'ha de subratllar, tanmateix, que els requeriments de MillàsRaurell per emprendre una reforma a fons de les estructures teatrals catalanes venien de lluny, que sempre havien tingut en compte les especificitats de l'art escènic i que s'havien proposat com un objectiu a llarg termini. En coherència amb aquests plantejaments, les reflexions i les actuacions de Millàs-Raurell dins d'aquesta esfera van ser prou diverses al llarg de setze anys per persuadir-nos de l'esperit possibilista que

${ }^{3}$ La publicació va ser, en algun cas, un gest de preservació. En una carta sense datar, que deu ser de 1926, adreçada a l'empresari Josep Canals, li notifica l'edició de La Llotja a La Revista, i hi argüeix: "no puc resignar-me a tenir en clausura, durant tant de temps fins ara i amb l'esperança d'un avenir il.limitat una obra que, francament, no m'avergonyeix." (Carta autògrafa de la col-lecció Canals, núm. 2639, dipositada al Fons Sedó del Centre de Documentació i Museu de les Arts Escèniques de la Diputació de Barcelona).

${ }^{4}$ La sorpresa d'Eva, que la companyia Vila-Daví va muntar al teatre Romea el I930, ja havia estat foguejada a l'escenari de l'Orfeó Gracienc el $1923 \mathrm{amb}$ el títol La fidelitat d'Elena, i La Llotja s'havia estrenat com Primer, la vanitat a la Societat Foment de Molins de Rei abans d'aterrar sobre les taules del Novetats $i$ abans, fins i tot, de publicarse a La Revista el 1926 mateix. Vegeu les vicissituds que va passar abans de no poder estrenar La Llotja a Picanyol. 
les guiava, i prou regulars com per encaixar-les dins d'una intenció programàtica. Des d'aquest punt de vista, no es pot fer estrany que part dels seus esforços busquessin l'empara d'una plataforma com l'Escola d'Art Dramàtic d'Adrià Gual que era, al capdavall, un dels intents amb més solta de regenerar el panorama teatral del Principat: la primera obra de Millàs-Raurell de la qual en tenim notícia, Les flames, va obtenir una menció honorífica en el concurs de l'Escola Catalana d'Art Dramàtic de I9I9 (“Concurs” ıo); la traducció de la versió dramatúrgica d'Els germans Karamazov de Jacques Copeau i Jean Croué es va editar dins les Publicacions de l'Escola el 1923 i la seva rúbrica va recalar esporàdicament en la pàgina d'Espectacles de La Veu de Catalunya, on Gual tenia una presència estel-lar. Més enllà dels testimonis privats d'admiració de la primera època, ${ }^{6}$ ignoro quin va ser el grau d'afinitat real entre els dos personatges, ni com es va descabdellar la seva relació en el període republicà, quan Millàs-Raurell esdevingué membre del Patronat que regia la Institució del Teatre. El que sí que tenim documentat és el rebuig que el veterà va demostrar vers el projecte de reorganització dels estudis de la Institució, elaborat per Millàs-Raurell, que prioritzaven la preparació dels actors i postergaven les altres activitats. ${ }^{7}$

Abans he al-ludit a les accions i a les reflexions de Millàs-Raurell. Les unes van lligades a les altres, com és lògic, encara que l'ostensible manca de prolixitat dels articles teòrics de l'escriptor ens parla ben a les clares del biaix pragmàtic, antiespeculatiu, de les seves formulacions. Enmig de l'enfadosa i monòtona atmosfera de plany per la crisi teatral del país, Millàs-Raurell instava a bandejar el retret "desfetista" dels més crítics i l'enganyosa idealització de les glòries pretèrites per "tancar-nos i treballar", mirant de posar les bases d'una cultura teatral que tingués prou entitat i qualitat com per no desentonar amb el que passava arreu ("L'esforç d'enguany" $25 \mathrm{i}$ "Temes teatrals" 25 ). A mitjan dècada dels vint tot semblava per fer, i per això el dramaturg desaconsellava l'exhibició de teatre català a París amb motiu de l'Exposició

5 Es veu que la distinció es va produir de manera força insòlita. Gual comenta a les seves memòries que aquell accèssit de dues-centes cinquanta pessetes no estava previst, $\mathrm{i}$ encara postil.la: "Mai no ens hem pogut explicar l'exemplaritat d'aquell fet, que únicament pogué ser fill de la condescendència d'algú extremadament bo prop de certes insistències més o menys oportunes” (290n).

${ }^{6}$ Es conserven dues cartes dels anys vint, adreçades a Gual, de to altament elogiós. La primera, datada el 22 de febrer de I92I, es refereix a la reposició de La fi de Tomàs Reynald en els següents termes: "L’obra era d'emoció, que és la matèria de les obres que no passen mai: deixeu-me que me'n feliciti. Un triomf vostre jo sempre l'he tingut per un triomf propi. Ja us he dit moltes vegades que sou vos a qui em sento més vinculat i a qui jo considero, en escena, el més intel.ligent i el més dominador" (epistolari d'Adrià Gual, vol. III, núm. I2r82, fol. I22. Fons Sedó del Centre de Documentació i Museu de les Arts Escèniques de la Diputació de Barcelona).

7 Vegeu Bransuela 4 . 
d'Arts Decoratives. ${ }^{8}$ Deu anys després es pot dir que els seus fronts de lluita no havien variat gota.

D'acord amb el parer de l'intelllectual, l'afany per trencar les inèrcies que paralitzaven l'escena catalana havia de ser compartit i voluntariosament empès des de les instàncies productores dels espectacles: calia que els intèrprets recuperessin el punt $\mathrm{i}$ la consciència sobre la seva "transcendental missió", que deixessin de gronxar-se en els amaneraments que els convertien en actors d'“un sol paper, un paper vagarós, diluit sense personalitat, procurant de fer de cada tipus que li donin, el seu propi caràcter" $i$ es decidissin a posar "ànima i matèria" sobre les taules ("Temes teatrals” 25). Calia que s'abandonessin la ronyosa pràctica d'aprofitar l'utillatge de vint-i-cinc anys enrere i les decoracions merament il.lustratives, i que, en escanvi, es concebessin escenografies amb volada estètica, inspirades en les idees sobre espai i moviment que s'imposaven arreu del món, des de l'estilització realista de Lee Simonson fins al constructivisme de Sergeevna Popova ("Temes teatrals" 25). Calia que els periodistes exercissin una crítica lleial i constructiva (“¿A què atribuïu ...”. 5). I calia, és clar, sobretot, que els empresaris entenguessin que el negoci que tenien a les mans també podia arribar a ser un art i que existia l'obligació moral de "renunciar, o fer semblant de renunciar a la facilitat $i$ anar a donar una producció digna" i "d'educar el públic" ("Temes teatrals" 27).

El convenciment que la fundació d'un teatre català "normal" passava per l'àrdua campanya d'instruir i reorientar el gust del públic, malmès per la comèdia grassa i el melodrama lacrimogen, per productes que aspiraven només a excitar les reaccions fisiològiques més primàries, va ser una constant en la trajectòria de Millàs-Raurell, i el cas és que fa tota la sensació que en el decurs dels anys l'escepticisme sobre les possibilitats d'afinar el paladar del públic nadiu es va aguditzar. Per aquest motiu posà de manifest la desconfiança en l'efectivitat d'iniciatives aillades com les subvencions oficials de la Conselleria de Cultura republicana o el projecte d'un teatre del proletariat (Martí Ferrer 4). No cal dir que l'autor mai no va ser tan ingenu com per imaginar una transformació dràstica $i$ generalitzada del paisatge escènic domèstic: prejudicis intellectuals i sentit pràctic el feien adonar que la deriva populista, que predominava entre els coquins empresaris catalans, era en bona mesura inesmenable. ${ }^{9}$ El que calia procurar, per tant, era que la hipotètica minoria d'exquisits pogués trobar el seu oasi

\footnotetext{
8 “... avui per avui a París nosaltres no hi tenim res a dur, si volem fer un bon paper" (M[adrid], "Encuestas" 4).

9 “Predomina, només, l'assegurar l'entrada del diumenge amb un mínimum de despeses. / No és que sigui condemnable l'esperit comercial en l'empresa. Al contrari: el dia que el nostre teatre trobi un director amb veritable temperament comercial el teatre català estarà salvat econòmicament" (M[adrid], "Encuestas" 4).
} 
estètic i que els models del Vieux Colombier, del Birmingham Repertory o del Guild de Nova York fossin trasplantables a Catalunya.

L’operació de les Vetllades Selectes del Teatre Català Romea, ideada segons crec per Millàs-Raurell de bon principi, es pot entendre en aquest sentit com un conat de revolució il-lustrada que es va tornar aiguapoll. A primera vista, les Vetllades representaven el punt dolç de la confluència entre tres mons distanciats: una empresa àvida d'ampliar el seu públic i d'atraure un espectador amb més poder adquisitiu, unes dames de l'alta societat seduides per la pàtina de prestigi que atorgava el mecenatge artístic $\mathrm{i}$ un parell d'intel-lectuals -Millàs-Raurell i el seu amic Carles Soldevila - neguitosos per fondre el reclosiment escènic català. Pel febrer de 1922, Millàs havia publicat un article a $\mathrm{La} \mathrm{Veu} \mathrm{que}$ semblava anunciar els propòsits pedagògics dels exclusius vespres del teatre del carrer de l'Hospital: "Caldria anar habituant”, escrivia,

el públic a un teatre bo, enc que fos fent-li conèixer, no les patotxades de més èxit a París - èxits per a turistes- sinó les obres, que amb un fons seriós, amb la garantia d'un nom, amb la garantia d'una crítica i àdhuc d'una lectura, servissin per a educar poc a poquet, les nostres gents a distingir el teatre d'un intermedi de pallassos de cinema. Per assolir aquesta educació - la qual a la vegada que fos del públic, seria del crític i de l'autor- proposaríem la constitució de una entitat a semblança (semblança administrativa i d'organització, perquè entre nosaltres ja tenim, en l'aspecte de teatre digne, la nostra petita tradició) del Vieux Colombier. ("Per un teatre millor" 7)

Com es veu, no es tractava d'aplicar una violenta teràpia de xoc, sinó de dosificar amb parsimònia els productes de qualitat per aconseguir un cenacle de gustos refinats que fixés una demanda exigent, s'expandís i impulsés l'europeïtzació del teatre indígena. La teràpia prescrita durant les temporades I922-1923 i I923-I924 va consistir en un tast d'obres de Charles Vildrac, Pierre Veber, Somerset Maugham, Luigi Pirandello o Franz Molnar, traduïdes per col-legues d'ofici com Soldevila, Josep M. de Sagarra, Josep Carner o Josep Pous i Pagès; a més de Fanny $i$ els seus criats de Jerome K. Jerome, d'Els germans Karamazov de Copeau i Croué i de l'Anna Christie d'Eugène O'Neill vessades al català per Millàs-Raurell mateix. Addicionalment, en la correspondència entre Carles Riba i Millàs dipositada a l'Arxiu Nacional de Catalunya encara es mencionen els noms de Franz Wedekind, August Strindberg, Arthur Schnitzler i Nikolai Gogol com a possibles incorporacions al selecte programa. La tria és, sens dubte, una eloqüent illlustració de l'eclecticisme de Millàs-Raurell a l'hora d'oferir estímuls renovadors i una significativa guia dels interessos estètics que van inspirar la seva pràctica escènica, però el fet és que, a desgrat de l'entusiasme dels coordinadors i fins del relatiu impacte mundà, cultural i polític que van aconseguir les compareixences de Pirandello i Vildrac en el marc 
d'aquesta campanya, les Vetllades no van exercir d'esperó actualitzador ni poc ni gaire, i les revifades de 1925 i 1928, episòdiques com són, no poden contradir-ho. ${ }^{\text {Io }}$ S'escapa dels propòsits d'aquestes línies diagnosticar les raons que varen sentenciar el final de la iniciativa, però ni que sigui com a conjectura provisòria es pot apuntar que mentre Soldevila parlava de les limitacions del públic per fer-se amb sensibilitats distintes ("El teatre i el públic" I), Sagarra s'havia lamentat més d'un cop de la matusseria de certs muntatges (6), i va coincidir amb Bertrana a l'hora de carregar els neulers a la inveterada improvisació de les posades en escena (IOI-O3).

Dins el mateix ordre de coses tampoc no es pot ignorar que algunes de les sessions de les Vetllades incomodaren els pudibunds espectadors del teatre i suscitaren alarmes que tal vegada contribuïren a la liquidació d'aquella empresa. De fet, Riba ja preveia catastròfiques conseqüències si gosaven estrenar La senyoreta Júlia. "Voleu dir", demanava retòricament a Millàs en una epístola escrita des de Munic, "que el burgès del Romea no ens tirarà les cadires pel cap? $\mathrm{O}$ que el teatre no es quedarà buit a la tercera escena?” (237). L'obra no es va estrenar $i$, de la traducció ribiana, no en queda, sembla, cap traça; no obstant això, és més que probable que els fets haguessin confirmat els aprensius vaticinis de l'eventual traductor si hem de jutjar en funció del testimoni que ens proporciona Bertrana de les representacions d'El Paquebot Tenacity i de Civilitzats, tanmateix! El crític de La Veu hi descrivia "el moviment tàcit de protesta per part d'alguns concurrents de les vetllades", motivat per "la vella qüestió de la moralitat artística" (B[ertrana]. 5). En contrapartida, Santiago Rusiñol, que no s'estava de relativitzar els escrúpols d'uns auditoris que, en aparença, podien tolerar quasi qualsevol contingut d'una funció estrangera, però que s'esgarrifaven així que els trobaven en obres en català, interrogava els organitzadors sobre l'audàcia real de la seva programació: "No us sembla, Soldevila i Millàs, que val la pena meditar aquestes coses, d'ésser valents del tot i no a mitges?" (Xarau I83).

Discutir ara la pertinència de les apreciacions de Rusiñol ens arrossegaria massa lluny, perquè tant Millàs com Soldevila ja havien escrit sobre el tema i perquè ambdós varen ser objectius freqüents dels dards dels moralistes en els anys que havien de venir. Diria que el que de debò interessa del cas és que, a despit del fet que ni Millàs-Raurell ni Soldevila s'havien proposat jugar la carta de la irreverència o de la provocació i que alguns dels projectes que van desestimar més aviat inclinen a creure que van eludir les peces més crues, tampoc no van acotar el cap davant les guitzes extemporànies. Sense anar més lluny,

${ }^{\text {Io }}$ Sobre aquests episodis concrets, vegeu Camps, Filippo, Gallina, Muñiz i Gibert. 
quan Millàs-Raurell va redactar el balanç de les primeres representacions de les Vetllades, va presentar l'afer com un assumpte de militància artística. El que venia a dir era que la modernització teatral catalana no es podia fer sense esgarrinxar els prejudicis del públic, i que era menester una actitud inflexible per assolir-la:

“Esteu satisfets o no de l'estat de coses actual? Si n'esteu realment contents, no ens amoïnéssim. Si no n'esteu: per què transigir ja des del començament, per què fer concessions als factors que ajuden a la crisi de la qual us queixeu? Cal assegurar-se de la conveniència de destruir el que existeix. Si l'enderroc és adoptat, no ens han de fer por les dimensions de la bomba" ("L'esforç d'enguany” 24-25). L'explosiva vehemència de les darreres frases s'entén si, en lloc de llegir-les com una invitació al terrorisme cultural, les llegim com la definició d'un principi deontològic i d'una actitud ètica. Millàs-Raurell maldava perquè la figura de l'intel-lectual en la societat catalana moderna obtingués ple reconeixement, però la seva era una batalla que, sense ignorar els interessos corporatius i professionals, feia passar al davant l'ascendent crític i ideològic, perquè, entre altres coses, l'autoritat moral només es podia obtenir des d'una innegociable integritat artística. Per aquest motiu, abominava de "l'autor [que] llença diatribes contra els causants de la crisi actual, però ell, revolucionari, agosarat abans, matisa les seves obres i entrega a l'empresa una obra llimadeta, acurada, fina, que no ferirà cap susceptibilitat" ("L'esforç d'enguany" 24-25).

L'individualisme creatiu, irreductible, és, ben mirat, un dels pals de paller de les idees de Millàs-Raurell sobre el que havia de ser el teatre, $i$ per més que l'autor demostrés un cop i un altre que estava perfectament informat de l'amenaçant preeminència que adquirien els directors nord enllà, no es mostrava menys ferm en el determini de no deixar-se prendre l'última paraula: "Sense literatura", afirmava després d'invocar els noms de Jean Giraudoux, George Bernard Shaw i Luigi Pirandello, "el teatre no té qualitat” (citat en Martí Ferrer 4). Per aquesta raó els elogis que prodigava cap als Pittoëff subratllaven la forma amb què els artistes posaven al servei del text la seva genialitat, l'excel-lència de la companyia provenia de la traça per "fer arribar l'obra, intacta, al cor i a la intel-ligència dels espectadors" ("L'art teatral dels Pittoëf” 4). I, en una línia similar, opinava que Elmer Rice feia santament de dirigir ell mateix Escenes de carrer, bo i evitant la interferència i el desig de protagonisme dels directors ("La tasca del director d'escena" 5). Comptat i debatut, la posada en escena no havia de ser per a Millàs-Raurell altra cosa que la vehiculació plàstica de les idees de l'autor.

La rotunditat de les posicions de Millàs-Raurell mereix una anàlisi molt més complexa de la que poden abastar aquestes pàgines. En el sòcol del seu irredemptisme textocentrista cal considerar, d'una banda, que Millàs-Raurell trobava que tot just estaven en una etapa embrio- 
nària, constitutiva, del teatre català i que, atesa la primor de la tradició pervinguda, l'absència de "primitius", que deia ell — de clàssics solvents, podríem dir nosaltres-, els excessos avantguardistes eren perillosos i es feia indispensable emmirallar-se en una gamma tan àmplia com fos possible de models contemporanis, susceptibles de fornir patrons relativament canònics $i$ temes pròxims a la sensibilitat coetània. Millàs va posar mans a l'obra traduint o adaptant una bona pila de novetats que havien de servir per orejar i fertilitzar l'atmosfera; Pirandello, Rice, Robert Cedric Sheriff, Ferdinand Bruckner, Simon Gantillon, Aleksandr Kuprin, entre d'altres. ${ }^{\text {II }}$

D'altra banda, i potser aquest és l'argument més determinant, Millàs-Raurell estava convençut que el teatre havia de ser intel-lectualment amfetamínic i, per torna, moralment revulsiu, i que això només es podia aconseguir per mitjà d'un discurs articulat i d'una selecció de temes pròxims, de motius matisadament familiars per a l'espectador, arrencats fins i tot, com és el cas de La sorpresa d'Eva (1930) o d'El món en què vivim de les pàgines dels diaris. És eloqüent, en aquest sentit, que el dramaturg projectés la publicació conjunta d'alguns dels seus drames sota el títol Històries del nostre temps ("La tasca feta" 7). En aquest punt, el dramaturg amb qui més podia coincidir era Ramon Vinyes, però a diferència de Vinyes, que detestava tot allò que semblés trivial —el drama burgès amb especial malvolença-, Millàs-Raurell no va fer cap fàstic als procediments més convencionals amb nivells molt diversos d'emancipació imaginativa: Apta per a senyores (1932) és una comèdia elegant explícitament deutora d'Oscar Wilde, La vida se'n va (1921) o Els fills (1928) recorren sense manies a suadíssims trucs melodramàtics. I és que, d'acord amb l'òptica de Millàs-Raurell, "el teatre té $j a$ una forma $i$ mil variacions i els seus problemes radiquen en els continguts d'aquesta forma" i "novetat no vol dir trencar els motllos de tot allò que ja existeix. Es poden respectar aquests motllos i millor (per a fer obra de durada), cal respectar els motllos i utilitzar-los. Posar dintre els vells càntirs aigua fresca. Tot és susceptible de caires infinits" ("Temes teatrals" 25).

En efecte, tot és susceptible de caires infinits a condició que l'autor “prengui una posició ben seva, ben original”. Vet aquí la síntesi de la poètica del dramaturg que va treballar a partir de la variació i el tempteig formal, engendrant peces tan distintes entre si com Xandí(1930), tragèdia gitana en un acte, i la ja mencionada La sorpresa d'Eva (1930). Que la diversitat formal era premeditada ho proven les repetides manifestacions de l'autor sobre l'organicitat de la seva producció - "veig les

II Ja el 1923, Octavi Saltor destacava el respecte de què Millàs era creditor "en sos estudis i aportacions de teatre estranger." O. S., "Els germans Karamazow, adaptació escènica en cinc actes de Dostoïewski, per Jacques Coupeau i Jean Croué”. 
obres com un conjunt i no com una munió de fraccions"- (Martí Martell 5) i per la manera de bromejar amb la desorientació estètica que li adjudicaven els crítics (Martí Ferrer 4). I el fet és que no cal sondejar molt a fons les obres per adonar-se que l'escriptor havia adoptat a consciència determinades premisses formals basades en la depuració. L'esporgament de tota mena de digressions, de monòlegs, d'aparts i de buates explicatives que ordenessin l'argument de manera tradicional va donar a les seves peces una austeritat que més d'un crític va titllar d'eixuta i que tot sovint va crear la impressió que les històries eren suggerides més que no explicades i que és construïen drames d'un sol personatge on la resta de figures quedaven massa difuminades. ${ }^{12}$ Les avaluacions no són pas desencertades, però allò que els crítics lamentaven com a tara constituïa una de les exploracions més ambicioses, $\mathrm{i}$ més revolucionàries dins del context català, per aclimatar els recursos escènics a tota una nova percepció de la realitat i de la intimitat, una percepció que basquejava per posar en escac les misèries de la falsa moral burgesa, evidenciades sense embuts a La mare de Hamlet (I93I) o a Fruita verda (I933), l'obra que tracta el suïcidi d'una adolescent embarassada i que fou retirada del Poliorama per l'exigència de l'Acadèmica de Ciències i Arts, propietària del teatre, que adduí la immoralitat de la peça ("La tasca feta" 7).

Més enllà, però, de l'airada denúncia social es tractava d'una percepció que qüestionava les velles seguretats ontològiques i epistemològiques. No és debades que Millàs-Raurell recordava que Freud i Einstein eren en l'arrel de les noves manifestacions artístiques (“Temes teatrals” 27) i que la consciència individual s'havia de convertir en matèria preferent per al creador. La Llotja (1926), d'indissimulable pedigrí pirandel-lià, va instal·lar Millàs-Raurell de ple en el vèrtex metateatral i al caire de la bancarrota de les convencions dramàtiques. Que l'autor decidís no portar fins a l'extrem la lògica desconstructiva no vol dir ni que la luxació artística no es mantingués com a mar de fons en totes les seves produccions ulteriors, ni que renunciés a la revolució dels codis expressius. Vol dir, més aviat, que va optar per l'única revolució que semblava plausible en la Catalunya d'aleshores: la de la utòpica normalitat.

NÚRIA SANTAMARIA

UNIVERSITAT AUTÒNOMA DE BARCELONA

${ }^{12}$ Per fer-se càrrec de les idees essencials de Millàs sobre dramatúrgia, vegeu Romeu (es tracta del resum d'una conferència que va dictar a l'Ateneu Polytechnicum) i les consideracions que amolla Millàs-Raurell (1928: 6) a partir d'una obra de Pompeu Crehuet. 
JOSEP M. MILLÀS-RAURELL, HOME DE TEATRE: LES INSURRECCIONS...

\section{REFERÈNCIES}

B[ERTRAnA]., P[rudenci]. “Revista d'espectacles”. La Veu de Catalunya 22 desembre 1922: 5 .

Bertrana, Prudenci. "El teatre”. Revista de Catalunya I3 (juliol i925): IOI-O3.

Bonnín, Hermann. Adrià Gual i l'Escola Catalana d'Art Dramàtic (1923-1934). Barcelona: Dalmau, I976.

Bransuela, L. M. "El Comitè de Teatre de la Generalitat de Catalunya”. ATS 2 (març-abril 1934): 4.

CAmps, A. "Luigi Pirandello en Cataluña: la razón de una incomprensión”. Revista de las Lenguas y Literaturas Catalana, Gallega y Vasca 5 (1998): 29-39.

“Concurs de l'Escola Catalana d'Art Dramàtic. Veredicte”. La Veu de Catalunya I4 agost I9I9: Io.

CurET, Francesc. “Josep $\mathrm{M}^{\mathrm{a}}$ Millàs-Raurell”. Història del Teatre Català. Barcelona: Aedos, 1967. 58I-82.

“El Premi 'Ignasi Iglesies' [sic] vist per Millàs-Raurell”. La Publicitat II febrer I936: I2.

FÀBRegAS, Xavier. Història del teatre català. Barcelona: Millà, 1978 . 258-60

FERRER, Martí. "La crisi del teatre català”. La Humanitat 25 desembre I93I: 4 .

Filippo, L. de. "Pirandello in Spagna”. Nuova Antologia 99 (juny 1964): 197-206.

GAlLÉN, Enric. “Millàs-Raurell”. Història de la Literatura Catalana. Part moderna. Dir. Joaquim Molas. Vol. IX, Barcelona: Ariel, 1987. 450-54.

Gallina, A. M. "Pirandello in Catalogna”. Atti del Congresso Internazionale di studi pirandelliani, 1967. 20I-208

GiBERT, Miquel M. “Charles Vildrac a Catalunya: aspectes de la recepció d'un autor intersticial". Gèneres $i$ formes en la literatura catalana d'entreguerres (1918-1939). I Simposi sobre traducció $i$ recepció en la literatura catalana contemporània. Ed. Miquel M. Gibert i Marcel Ortín. Lleida: Punctum \& Trilcat, 2005. I3I-43.

GuAL, Adrià. Mitja vida de teatre. Memòries, Barcelona: Aedos, 1960. IRIBARREN I DONADEU, Teresa. "Josep Millàs-Raurell, pioner en la recepció creativa de Joyce”. El Contemporani 30 (juliol-desembre 2004): 48-52.

“La tasca feta i la que pensa fer Millàs-Raurell”. La Humanitat 17 març I935: 7.

M. “El perquè Millàs-Raurell retirà 'El món en què vivim””. Mirador 29 setembre 1935: 2.

M[ADRID], F[rancisco]. "Encuestas. Lo del teatro catalán llevado a París”. La Noche 25 juliol i925: 4. 
MANENT, Albert. “Millàs-Raurell, un escriptor del nou-cents”. Avui 4 setembre 1996: 38 .

MarTell, Martí. [Miquel Duran i Tortajada]. "Millàs-Raurell estrena avui La Llotja a Novetats”. La Veu de Catalunya, I7 febrer I928: 5 (ed. vespre).

Millàs-RAURELL, Josep M. “¿A què atribuïu la crisi del teatre català? ¿Què caldria fer per tal de redreçar-lo?”. La Humanitat I4 desembre I933: 5 .

-. "L'art teatral dels Pittoëf". La Veu de Catalunya 28 gener 1927: 4.

-. "L'esforç d'enguany". La Revista I75-176 (I-I6 gener I923): 24-25.

—. "Arguments i personatges". La Publicitat 7 desembre 1928: 6.

—. “La tasca del director d'escena”. Mirador 22 (27 juny I929): 5.

-. "Per un teatre millor". La Veu de Catalunya 22 febrer I922: II.

-. “Temes teatrals". La Revista XIV (gener-juny I928): 24-30.

MuÑIZ, M. N. "Sulla ricenzioni di Pirandello in Spagna (Le prime traduzioni)”. Quaderns d'Itàlia 2 (1997): II3-48.

PICANYOL, Xavier. "Millàs-Raurell ens parla de La Llotja, i ens explica altres coses força interessants". La Nau 2I febrer 1928: I.

PONS, Agustí. "Millàs-Raurell, com un serial dels d'ara”. Avui zi gener 1997: 42.

RibA, Carles. “Carta del 8 de desembre de i922”. Cartes de Carles Riba I: $1920-1938$. Ed. Carles-Jordi Guardiola. Barcelona: La Magrana, I990. 237.

RomeU, Bru. "El teatre dels nostres temps”. El Matí 3 juliol i929: 4.

SAGARrA, Josep M. de. "Romea. Última vetllada selecta”. La Publicitat 26 juny I923: 6

$\mathrm{S}$ [ALTOR], O[ctavi]. "Els germans Karamazow, adaptació escènica en cinc actes de Dostoïewski, per Jacques Coupeau i Jean Croué; trad. de J. Millàs-Raurell. (Publicacions de l'E. C. d'A. D.)”. La Revista I83-I8 (I-I6 maig I923): IO2

Soldevila, Carles. "Full de dietari. El teatre i el públic". La Publicitat I8 gener I924: I.

XARAU [Santiago Rusiñol]. “Glosari. Vetllades Selectes”. L'Esquella de la Torratxa 2270 (I7 setembre I922): I83. 